\title{
Tandem autologous stem cell transplantation in multiple myeloma after high-dose chemotherapy with two separate collections: single institution experience
}

\author{
M. LADICKA, V. BALLOVA, L. DRGONA, A. VRANOVSKY, J. LAKOTA* \\ Bone Marrow Transplantation Unit, National Cancer Institute, Bratislava, Slovakia \\ *Correspondence: jan.lakota@ba.sanet.sk
}

Received February 16, 2012 / Accepted April 2, 2012

\begin{abstract}
Presented is a retrospective analysis of multiple myeloma patients transplanted at our institution between November 1993 and August 2007. The objective of this analysis was to assess the feasibility and toxicity of tandem autologous stem cell transplantation (T-ASCT) when stem cells were harvested before first and before second transplantation separately. A total of 90 patients transplanted in our center were analyzed, of whom 43 patients were in tandem transplantation group.

The overall response rate (ORR) was $83.7 \%$ and $95.1 \%$, estimated five-year overall survival (OS) was $40.1 \%$ and $60.0 \%$, probability of five-year event-free survival (EFS) was $18.2 \%$ and $25.6 \%$, transplant related mortality (TRM) was $6.3 \%$ and $4.6 \%$ in the single and tandem transplant group, respectively. In multivariable analysis of all 90 patients, tandem transplantation and ORR attained after induction therapy were favourable prognostic factors for OS $(\mathrm{p}=0.024$ and $\mathrm{p}=0.002)$ and $\mathrm{EFS}$ $(\mathrm{p}=0.036$ and $\mathrm{p}=0.008)$, respectively.

In conclusion, tandem transplantation with two separate stem cell harvests, performed separately before the each transplantation, is feasible in majority of patients with acceptable toxicity.
\end{abstract}

Key words: multiple myeloma, high-dose chemotherapy, autologous stem cell transplantation, single and tandem transplantation

The treatment outcome in patients with multiple myeloma (MM) has been improved in the last decades. High-dose chemotherapy followed by autologous stem cell transplantation (ASCT) remains the standard of care for patients with age under 65-70 years even in the era of new drugs. ASCT compared to conventional chemotherapy led into improvements in complete remission rate $(\mathrm{CR})(1,2,3,4,5,6)$, progressionfree survival (PFS), event free survival (EFS) $(1,3,4,5,6)$ and prolonged overall survival (OS) $(1,3,4,5)$. Optimal utilization and increased antimyeloma efficacy of ASCT has been studied in multiple trials. Melphalan $200 \mathrm{mg} / \mathrm{m}^{2}$ became the preferred drug of preparative regimens before ASCT according to the results of studies with ASCT in MM $(7,8)$. Trials, comparing tandem autologous stem cells transplantation (T-ASCT) versus single autologous stem cells transplantation (S-ASCT) in up-front treatment for MM, confirmed the benefit of T-ASCT in EFS (9) and OS (10). In Bologna 96 trial, patients with a complete response/near complete response (CR/nCR) did not benefit from second transplantation with regard to EFS and relapse free survival (9). Patients achieving at least a very good partial response (VGPR) after the first transplantation had similar outcome with regard to OS with or without TASCT, according to the results of IFM94 trial (10).

The harvest of peripheral blood stem cells (PBSC) for tandem transplantation was performed before the first transplantation for both transplants in majority of the treatment protocols $(9,10)$. The main goal of this approach was to decrease the risk of failure of PBSC mobilization after the first ASCT, when stem cell damaging treatment had been used (11).

We report our retrospective analysis of all patients with multiple myeloma who were transplanted at the National Cancer Institute Bratislava with special emphasis on outcome of patients with T-ASCT who had two different harvests of PBSC for the each transplantation separately.

\section{Patients and methods}

Patients. All 90 patients with MM stage I-III who were transplanted at our institution between November 1993 and 
August 2007 were enrolled to this retrospective analysis. Adequate organ function was required with left ventricular ejection fraction of $>50 \%$, diffusing capacity of the lung for carbon monoxide $>50 \%$, no evidence of active hepatitis infection, negative HIV testing and a Karnofsky performance score of $>60 \%$. Renal dysfunction was not an exclusion criterion. Signed informed consent was obtained prior to transplantation according to the institutional guidelines.

Treatment. Patients were initially treated with three or four courses of induction chemotherapy VAD: vincristine at the total dose of $0.4 \mathrm{mg}$ (as a continuous intravenous infusion or as a bolus injection), doxorubicin $9 \mathrm{mg} / \mathrm{m}^{2}$ (as a continuous intravenous infusion or as a short infusion) for 4 consecutive days and dexamethasone $40 \mathrm{mg}$ (given orally or as an intravenous infusion) on the days 1-4, 9-12 and 1720. The treatment was repeated every 4 weeks. Pretransplant mobilization chemotherapy consisted of cyclophosphamide $2-2,5 \mathrm{~g} / \mathrm{m}^{2}$ i.v. with uromitexan rescue and hydration. PBSC were collected after priming with granulocyte colony- stimulating factor (G-CSF) $5 \mu \mathrm{g} / \mathrm{kg}$ s.c. per day. The G-CSF was started on day 10-13. Leukapheresis was performed with the target yield of more than $2 \times 10^{6} \mathrm{CD} 34^{+} / \mathrm{kg}$. Conditioning regimen consisted of high-dose melphalan $200 \mathrm{mg} / \mathrm{m}^{2}$ i.v. divided into 2 doses on the day -4 and -3 . Autologous stem cells were reinfused on the day 0 . All patients received G-CSF ( $5 \mu \mathrm{g} / \mathrm{kg}$ s.c. per day) from day 0 until the absolute neutrophil count reached at least $1000 \mu \mathrm{l}$ for 2 consecutive days. After full granulocyte and platelet recovery patients received the second course of cyclophosphamide $2-2.5 \mathrm{~g} / \mathrm{m}^{2}$ i.v. followed by the second PBSC mobilization. The second transplantation was administered within six months from the first transplant. The conditioning regimen consisted of melphalan 140 to $200 \mathrm{mg} / \mathrm{m}^{2}$ i.v. in a single dose on the day -3 or in two divided doses on the day -4 and -3 .

Antimicrobial prophylaxis and treatment of infection during the transplantations was applied according to the institutional guidelines. All blood products were irradiated with the dose of $30 \mathrm{~Gy}$. Platelets were administered when the platelet count was $<20,000 / \mu$ lor in case of bleeding, and red blood cells were substituted when hemoglobin was $<90 \mathrm{~g} / \mathrm{l}$.

Response criteria. Complete remission was defined as an absence of detectable monoclonal protein band in the serum and urine by immunofixation, absence of monoclonal plasma cells in the bone marrow aspirate and no increase in the size or number of osteolytic lesions. Partial remission was defined as a reduction of at least $50 \%$ of monoclonal protein in the serum, reduction of at least $90 \%$ of the light chain excretion in urine, more than $50 \%$ reduction of bone marrow infiltration by monoclonal plasma cells. Stable disease was defined as status of patients who neither have achieved partial remission nor were without progression. Chemosensitive disease was defined as any response to induction treatment. Relapse was defined as reappearance of plasma cells in the bone marrow or monoclonal paraprotein band in the serum or urine of patients who had achieved CR. Progression was defined as an increase in any disease marker or necessity of the new antimyeloma treatment in patients with PR.

Statistical analysis. The primary end point of this analysis was OS. OS was calculated from the date of the first transplantation (in a tandem transplantation) or from the date of transplantation (in a single transplantation) until the date of death from any cause or last follow-up. The secondary end points were EFS and identification of prognostic factors influencing survival. Event-free survival was defined as the time from transplant to progression or relapse of myeloma or death from any reason. Death within 100 days after transplantation (either single or second transplantation) was classified as transplant-related mortality (TRM).

The basic monitored parameters, median, minimum and maximum, were performed according to frequency figures and describing statistics. Survival of patients was estimated by the Kaplan-Meier survival curve (12). Survival differences were examined by the long-rank test. All statistical tests were two-tailed.

The basic monitored variables with quantitative response are described either as mean \pm standard deviation (SD) or median and a (quartile 1 - quartile 3 ) range. Categorical data are presented as counts and relative frequencies (percentages). Survival rates in both investigated groups were estimated with unconditional Kaplan-Meier survival method. Results are presented as respective survival plots and survival differences were examined by the long-rank test. Continuous baseline characteristics, which were assumed to influence survival, were tested for differences between the groups with unpaired t-test. The association of selected categorical variables with the treatment strategy (the group classifier) was judged by chi-square analysis. The relationship between survival and selected predictors was afterwards examined by Cox's regression model with included baseline covariates. A statistical hypothesis testing was performed at the alpha level of 0.05. All statistical tests were two-tailed (where applicable).

\section{Results}

Clinical characteristics. We performed retrospective analysis of multiple myeloma patients transplanted at our institution between November 1993 and August 2007, to determine outcome of patients after single and tandem transplantation. Forty-three patients underwent tandem transplants and 47 patients received single transplantation only. Patient characteristics are given in Table 1 . The median interval between the first and second transplant was 5 months (range, 3-7). The median follow-up time from ASCT in the single and from the first transplant in the tandem group was 34.0 (range, $0.5-169.0+$ ) and 54 months (range, 4.0-164.0+), respectively. Four patients were lost to follow up.

Completion of therapy. Seven (14.9\%) patients in the single transplant group and $6(13.9 \%)$ patients in the tandem group were pretreated with different multidrug treatment regimens. 
Irradiation before the first transplantation was applied in 14 patients with S-ASCT and in 17 patients with T-ASCT. Median dose of melphalan was $200 \mathrm{mg} / \mathrm{m}^{2}$ (range: 110-200 $\mathrm{mg}$ ) in the single group and $200 \mathrm{mg} / \mathrm{m}^{2}$ (range: $150-200 \mathrm{mg}$ ) in the tandem group before first transplantation. The median dose of melphalan as preparative regimen before the second transplant was $160 \mathrm{mg} / \mathrm{m}^{2}\left(140 \mathrm{mg} / \mathrm{m}^{2}\right.$ in 7 patients; $160 \mathrm{mg} / \mathrm{m}^{2}$ in $14 ; 200$ $\mathrm{mg} / \mathrm{m}^{2}$ in 19 patients). Two patients received BEM as preparative regimen before the second transplantation (carmustine $300 \mathrm{mg} / \mathrm{m}^{2}$ i.v. on day -7 , etoposide $100 \mathrm{mg} / \mathrm{m}^{2}$ twice daily i.v. on days -6 to- 3 and melphalan $140 \mathrm{mg} / \mathrm{m}^{2}$ i.v. on day -3 ) and 1 patient received CBV (carmustine $300 \mathrm{mg} / \mathrm{m}^{2}$ i.v. on day-6, etoposide $200 \mathrm{mg} / \mathrm{m}^{2}$ twice daily i.v. on day- 5 to -3 , cyclophosphamide $1600 \mathrm{mg}$ i.v. on day -5 to -3 ). Seventeen patients (8 patients in S-ASCT and 9 patients in T-ASCT) received interferon- $\alpha$ as maintenance treatment. CD34-positive selection of the stem cells was performed in 9 patients. One patient in the tandem group had syngeneic transplantation.

The second transplantation was performed in 43 (55.8\%) of 77 patients, planned for tandem transplantation. The most frequent reason for omission of the planned second transplantation was refusal of treatment in 12 patients. Two patients intended for T-ASCT had progression of MM at the time of $2^{\text {nd }}$ transplant. Two patients had delayed second transplant 8 and 11 months after the first transplantation, therefore they were not included into the T-ASCT group. Overview of the treatment protocol is shown in Figure 1.

Treatment results. The response rates before and after transplantations are shown in Table 2. Overall response rate (CR+ PR) after induction was $87.2 \%$ and $79.1 \%$ in the single and tandem group, respectively. The overall response rate after transplantation was $83.6 \%$ in the single group and $95.1 \%$ in the tandem group.

The probability of 5-year OS after transplantation in the whole cohort was $50.6 \%$, in S-ASCT $40.1 \%$ and $60.0 \%$ for TASCT. The median OS was 79 (95\% CI 42-169), 39 (95\% CI 30-169) and 137 (95\% CI 57-164) months for the whole cohort, S-ASCT and T-ASCT, respectively. The probability of 5-year EFS was $21.3 \%$ in the whole cohort, $18.2 \%$ for S-ASCT and $25.6 \%$ for T-ASCT. The median EFS was 22 (95\% CI 15-26), 14 (95\% CI 11-21) and 25.6 (95\% CI 19-35) months for the whole cohort, S-ASCT and T-ASCT, respectively. Figures 2, 4 and 3, 5 show curves for EFS and OS, for the whole cohort of patients and with respect to number of performed transplants, respectively.

Table 3 shows results of multivariable analysis of prognostic factors for EFS and OS using the Cox regression model. We identified two variables which remained predictive both for the OS and EFS. These 2 favorable prognostic factors were tandem transplantation (HR for OS was 0.48 ; 95\% CI $0.25-$ $0.91 ; \mathrm{p}=0.024$ and HR for EFS was $0.59 ; 95 \%$ CI $0.36-0.97$; $\mathrm{p}=0.036)$, response (CR, PR and chemosensitivity) achieved before transplantation (HR for OS was 0.32 ; $95 \%$ CI 0.16-0.66; $\mathrm{p}=0.002$ and $\mathrm{HR}$ for $\mathrm{EFS}$ was $0.44 ; 95 \%$ CI $0.24-0.80 ; \mathrm{p}=0.008$ ), respectively. Age over 60 years negatively influenced OS (HR 2.04; 95\% CI 0.95-4.40; $\mathrm{p}=0.069$ ).
Table 1. Basic characteristic of the patients

\begin{tabular}{|c|c|c|c|}
\hline \multirow[t]{2}{*}{ Characteristics } & $\begin{array}{c}\text { Total } \\
\text { (90 patients) }\end{array}$ & $\begin{array}{c}\text { Single } \\
\text { transplantation } \\
\text { (47 patients) }\end{array}$ & $\begin{array}{c}\text { Tandem } \\
\text { transplantation } \\
\text { (43 patients) }\end{array}$ \\
\hline & \multicolumn{3}{|c|}{ No. of patients (\%) } \\
\hline \multicolumn{4}{|l|}{ Sex } \\
\hline Female & $50(55)$ & $33(70)$ & $17(39)$ \\
\hline Male & $40(44)$ & $14(29)$ & $26(60)$ \\
\hline Age (yrs) & $54(25-69)$ & $58,5(40-69)$ & $50(25-68)$ \\
\hline \multicolumn{4}{|l|}{ M-protein } \\
\hline IgG & $51(56.6)$ & $26(55,3)$ & $25(58.1)$ \\
\hline $\operatorname{IgA}$ & $23(23.3)$ & $13(27,6)$ & $10(23.2)$ \\
\hline IgM & $2(2.2)$ & $0(0.0)$ & $2(4.6)$ \\
\hline IgD & $1(1.1)$ & $1(2.1)$ & $0(0.0)$ \\
\hline Non secretory & $2(2.2)$ & $1(2.1)$ & $1(2.3)$ \\
\hline Free light chain & $11(12.2)$ & $6(12.7)$ & $5(11.6)$ \\
\hline \multicolumn{4}{|l|}{ Salmon and Durie stage } \\
\hline I & $10(11.1)$ & $5(10,6)$ & $5(11.6)$ \\
\hline II & $3(3.3)$ & $1(2,1)$ & $2(4.6)$ \\
\hline III & $77(85.5)$ & $41(87.2)$ & $36(83.7)$ \\
\hline Renal failure & $15(16.6)$ & $10(21,3)$ & $5(11.6)$ \\
\hline Plasmocellular leukemia & $2(2.2)$ & $1(2,1)$ & $1(2.3)$ \\
\hline Syngeneic transplantation & $1(1.1)$ & $0(0.0)$ & $1(2.3)$ \\
\hline \multicolumn{4}{|l|}{ CD 34+ selection in } \\
\hline $1^{\text {st }}$ transplantation & $9(10)$ & $1(2,1)$ & $8(18.6)$ \\
\hline $2^{\text {nd }}$ transplantation & $3(3.3)$ & $0(0.0)$ & $3(6.9)$ \\
\hline $\begin{array}{l}\text { Irradiation before } \\
\text { transplatantion }\end{array}$ & $31(34.4)$ & $14(29.8)$ & $17(39.5)$ \\
\hline \multicolumn{4}{|l|}{ Transplantation as } \\
\hline $1^{\text {st }}$ line & $76(84.4)$ & $40(85.1)$ & $36(83.7)$ \\
\hline$>1^{\text {st }}$ line & $14(15.6)$ & $7(14.9)$ & $7(16.3)$ \\
\hline
\end{tabular}

Abbreviations: Ig, immunoglobulin

Table 2. Outcome according to the remission status

\begin{tabular}{lcc}
\hline Variable & $\begin{array}{c}\text { Single-Transplant } \\
\text { Group }\end{array}$ & $\begin{array}{c}\text { Tandem-Transplant } \\
\text { Group }\end{array}$ \\
\hline Before first transplantation & \multicolumn{2}{c}{ No. of patients $(\%)^{*}$} \\
Complete remission & $5(10.6)$ & 43 \\
Partial remission & $17(36.2)$ & $4(9.3)$ \\
Chemosensitive disease & $19(40.4)$ & $16(37.2)$ \\
Non-rensponders (PD+SD) & $6(12.8)$ & $9(32.6)$ \\
\hline After first transplantation & 43 & 43 \\
Complete remission & $18(41.9)$ & $15(34.9)$ \\
Partial remission & $18(41.9)$ & $23(53.5)$ \\
Non-rensponders (PD+SD) & $7(16.2)$ & $5(11.6)$ \\
\hline Final evaluation after therapy & 43 & 41 \\
Complete remission & $18(41.9)$ & $19(46.3)$ \\
Partial remission & $18(41.9)$ & $20(48.8)$ \\
Non-rensponders (PD+SD) & $7(16.2)$ & $2(4.9)$ \\
\hline
\end{tabular}

${ }^{*}$ only patients alive at the time of response evaluation

Abbreviations: PD, progressive disease; $\mathrm{SD}$, stable disease

Treatment-related toxicity. TRM was $6.3 \%$ in S-ASCT group (one patient due to colitis, 2 patients due to multiorgan failure) and $4.6 \%$ in T-ASCT group (one patient 


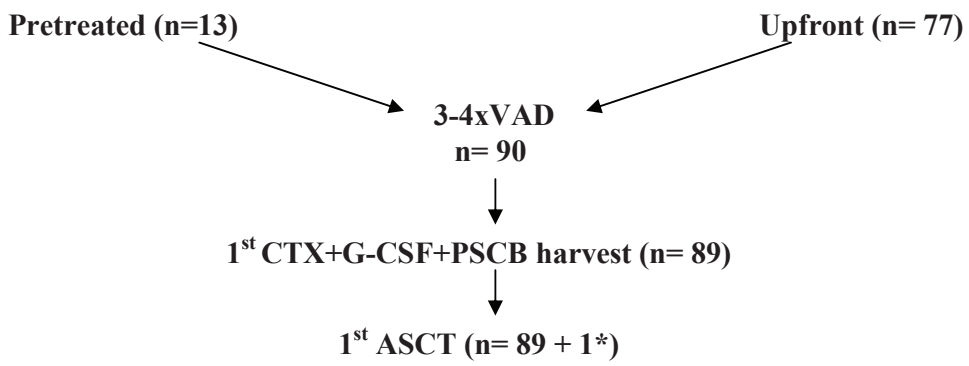

Omission of planned harvest $(n=22)$, reasons: Patient's refusal $(n=12)$

Progression $(\mathrm{n}=2)$

Technical problems with venous access $(n=1)$

Toxicity after $1^{\text {st }}$ ASCT

Prolonged thrombocytopenia $(n=3)$

Early death (TRM) $(\mathrm{n}=3)$

Arrhythmia G3 (n=1)

\section{No harvest $(\mathbf{n}=10)$}

Harvest failure $(\mathrm{n}=8)$

Progression $(\mathrm{n}=1)$

Patient's refusal $(n=1)$
No planned harvest $(n=13)$, reasons:

Renal failure with dialysis $(\mathrm{n}=2)$

Participation in clical trial $(n=2)$

Age $\geq 65$ years $(n=9)$

Figure 1. Overview of the protocol for multiple myeloma patients

* one patient received tandem syngeneic transplantation

Abbreviations: VAD, Vincristine, Doxorubicin, Dexamethasone; CTX, Cyclophosphamide;

G-CSF, Granulocyte Colony- Stimulating Factor; PBCS, Peripheral Blood Stem Cells; HD, High-Dose; ASCT, Autologous Stem Cell Transplantation; GI,

Gastrointestinal

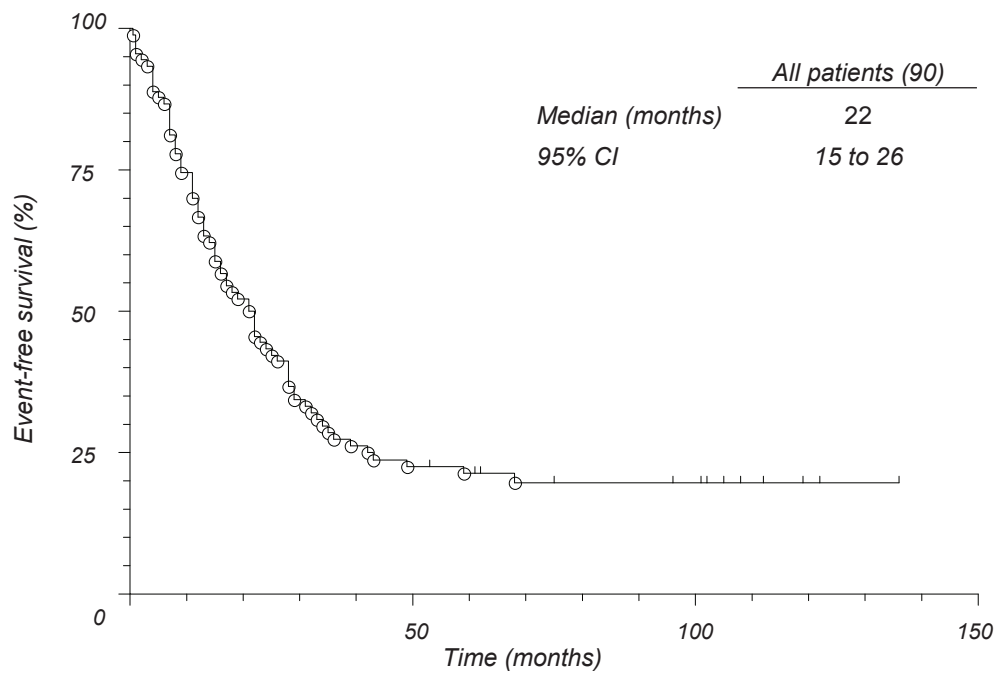

Figure 2. Kaplan-Maier estimate of event-free survival for all patients 


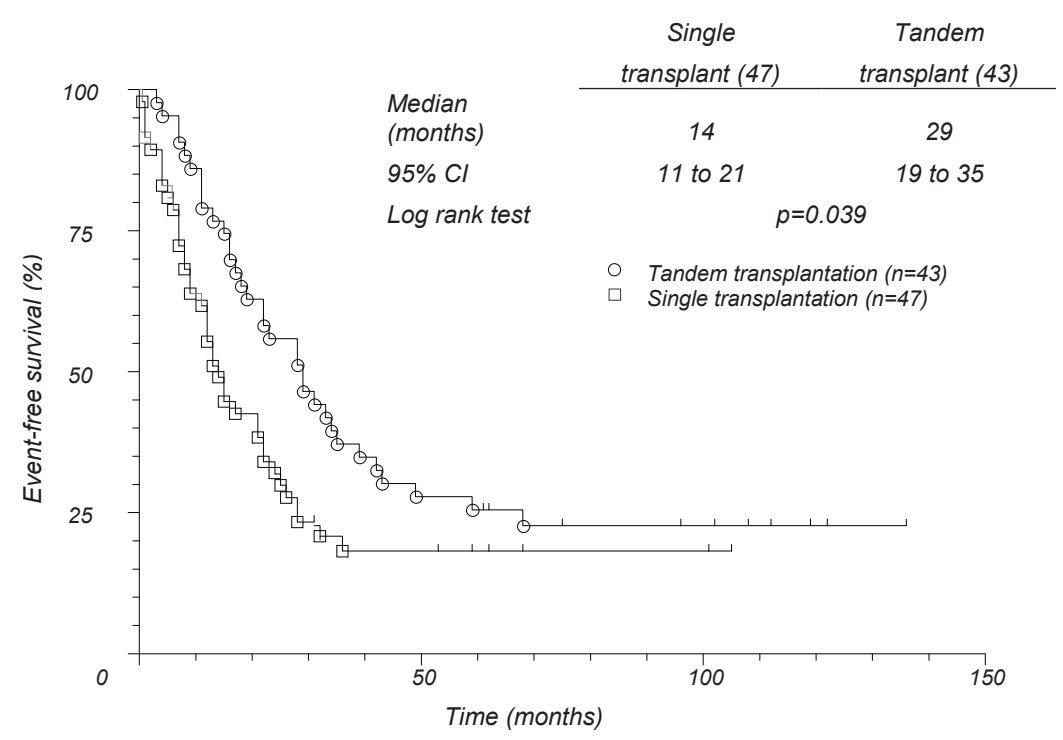

Figure 3. Kaplan-Maier estimate of event-free survival for single and tandem transplant

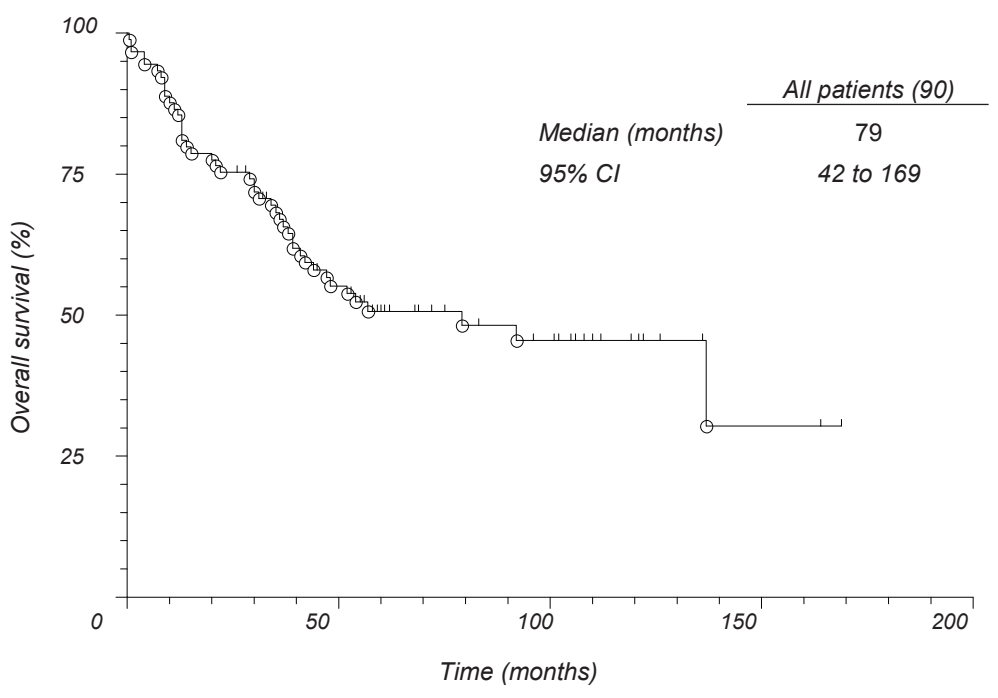

Figure 4. Kaplan-Maier estimate of overall survival for all patients

due to appendicitis with subsequent peritonitis and one due to pneumonia). Febrile neutropenia was observed in $36(76.6 \%)$ patients in single transplant group and in 36 $(60.4 \%)$ patients after the first transplantation in tandem transplant group. Thirty-two patients (74.4\%) of the tandem transplant group had neutropenic fever after the second transplant.

The median time to neutrophil count $\geq 500 / \mu \mathrm{l}$ was 16 days (range, 10-34) and thrombocytopenia $(<30000$ platelets/ $\mu$ l) was shorter than 30 days in $29(65.9 \%)$ patients in the single arm. Neutrophil count $\geq 500 / \mu \mathrm{l}$ was reached in $13(8-24)$ and 19 (10-52) days for the first and second transplantation in tandem arm, respectively. Duration of thrombocytopenia $(<30000$ platelets/ $\mu$ l) shorter than 30 days was in $40(93.0 \%)$ and $14(35.0 \%)$ patients for the first and the second transplantation, respectively. Hematologic toxicity wasn't evaluated in 3 patients in the single arm and 2 patients in the second arm because of the TRM, in one patient in tandem group was prolonged hematologic recovery.

There were $3(6.3 \%)$ cases of secondary malignancies in the single transplant group with one case of acute myeloblastic leukemia, one patient with chronic myelomonocytic leukemia and one patient had a cancer of unknown primary. 


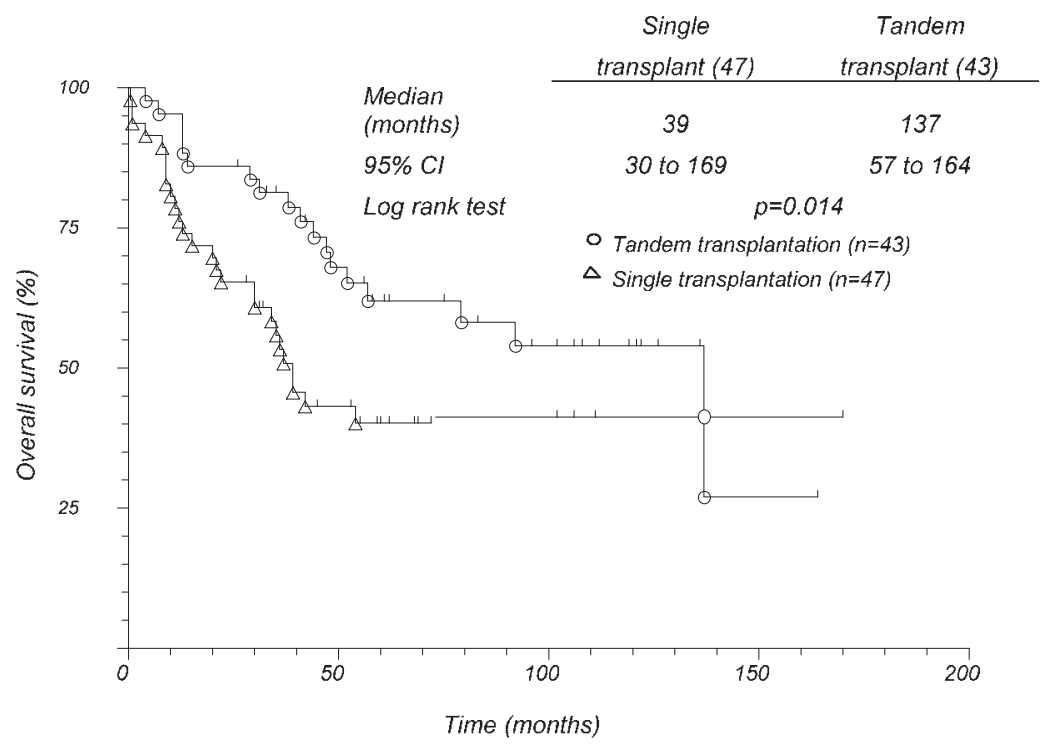

Figure 5. Kaplan-Maier estimate of overall survival for single and tandem transplant

Myelodysplastic syndrome developed in 4 (9.3\%) patients, one patient was diagnosed with prostate cancer and one with renal carcinoma, all in the tandem group.

Salvage therapy. Two patients of the 47 in the single transplant group received the second transplant at the time of progression, 26 and 78 months after the first ASCT. Two patients underwent non-myeloablative allogeneic stem cell transplantation 10 and 38 months after ASCT.

In one patient from the T- ASCT group we performed $3^{\text {rd }}$ autologous transplant with CBV conditioning 45 months

Table 3. Multivariable analysis of factors potentially affecting the clinical outcome

\begin{tabular}{|c|c|c|c|}
\hline Variable & Hazard Ratio & $95 \% \mathrm{CI}$ & $P$ \\
\hline \multicolumn{4}{|l|}{ Overall survival } \\
\hline Tandem transplantation & 0.48 & 0.25 to 0.91 & $=0.024$ \\
\hline $\begin{array}{l}\text { Response before transplantation } \\
\text { (CR, PR, CHS) }\end{array}$ & 0.32 & 0.16 to 0.66 & $=0.002$ \\
\hline Free light chain MM & 1.99 & 0.83 to 4.79 & $=0.121$ \\
\hline Creatinine $<177 \mu \mathrm{mol} / \mathrm{l}$ & 0.55 & 0.25 to 1.21 & $=0.138$ \\
\hline Stage I-II/III & 0.92 & 0.55 to 1.55 & $=0.762$ \\
\hline Age $>60$ years & 2.04 & 0.95 to 4.40 & $=0.069$ \\
\hline \multicolumn{4}{|l|}{ Progression free survival } \\
\hline Tandem transplantation & 0.59 & 0.36 to 0.97 & $=0.036$ \\
\hline $\begin{array}{l}\text { Response before transplantation } \\
\text { (CR, PR, CHS) }\end{array}$ & 0.45 & 0.24 to 0.84 & $=0.013$ \\
\hline Free light chain MM & 1.88 & 0.94 to 3.78 & $=0,074$ \\
\hline Creatinine $<177 \mu \mathrm{mol} / 1$ & 0.78 & 0.40 to 1.49 & $=0.448$ \\
\hline Stage I-II/III & 0.86 & 0.60 to 1.24 & $=0.417$ \\
\hline Age $>60$ years & 1.24 & 0.65 to 2.33 & $=0.493$ \\
\hline
\end{tabular}

Abbreviations: MM, multiple myeloma; CR, complete remission; PR, partial remission; $\mathrm{CHS}$, chemosensitive disease after first transplantation. Novel agents were used at the time of relapse in 12 patients (25.5\%) from the single ASCT group (thalidomide, $\mathrm{n}=10$ and/or bortezomib, $\mathrm{n}=6$ and/or lenalinomide, $\mathrm{n}=1)$ and in 19 patients (44.1\%) from the tandem group (thalidomide, $\mathrm{n}=17$ and/or bortezomib, $\mathrm{n}=8$ and/or lenalinomide, $n=3$ ).

\section{Discussion}

The present study is based on data collected from all patients treated with autologous stem cell transplant for multiple myeloma at our institution for the duration of 14 years.

It is well-known that number of mobilized CD34+ cells is adversely affected by previous administration of some cytotoxic drugs. Therefore, it is generally recommended to avoid use of stem-cell damaging agents such as melphalan in candidates for autologous transplantation (13). This is the reason why in most clinical trials the PBSC's for planned tandem autologous transplantation are collected before the first transplant $(9,10)$. Contrary to this recommendation are results of the study in which stem cell collection was adequate after priming with melphalan at the dose of $60 \mathrm{mg} / \mathrm{m}^{2}(14)$.

In our study the PBSC collection procedure failed in 8 patients due to lack of response to G-CSF after $1^{\text {st }}$ ASCT. Three patients after the first ASCT were not eligible for second mobilization due to prolonged thrombocytopenia. These two groups of patients $(8+3)$ present minority $(14.3 \%)$ of 77 patients planned for T-ASCT. Our data have shown that collection of PBSC within 3-6 months after $1^{\text {st }}$ ASCT is possible.

In the light of new information about prognostic factors for MM it is still an open question which subset of patients with MM can profit from second transplantation. Historically, patients not achieving CR or VGPR after the first transplant 
are candidates for T-ASCT $(9,10)$. According to results of multivariable analysis of our study, patients who responded to induction treatment before transplantation profited by highdose therapy more than those who did not achieve remission before transplant. Unfortunately, we could not make detailed analysis of currently standard laboratory tests since they were not available at the time when majority of our patients were treated.

In our analysis we also compared groups with T-ACST and S-ASCT with regard to OS and EFS. The T-ASCT induced longer survival than S-ASCT in both parameters (OS; $\mathrm{p}=$ 0.014 and EFS; $\mathrm{p}=0.039$ ). The probability of OS and EFS after 5 years was $40.1 \%$ and $18.2 \%$ for the single transplant, $60.0 \%$ and $25.6 \%$ for the tandem transplant, respectively. These data are consistent with the results of the IFM 94 trial reported by Attal et al (10) and the study reported by Regelink and Huijgens et al $(15,16)$. In the IFM 94 trial, 7-year probability of OS and EFS for patients assigned to the S-ASCT was 21\% and $10 \%$, respectively, and to T-ASCT $42 \%$ and $20 \%$, respectively. Significant benefit was confirmed for T-ASCT in OS ( $p=0.01)$ and EFS ( $\mathrm{p}=0.03)(10)$. In the following analysis of the abovementioned trial, the second transplant was supported by PBSC harvested after the first transplant (16). According to second analysis of both transplant groups, they were able to show significantly better OS and EFS in patients with T-ASCT (OS, $34 \%$ vs $18 \%$; EFS, $18 \%$ vs $0 \%$; both $\mathrm{p}<0.001$ ). Compared to Regeling et al, we assume that long-term control of MM in T-ASCT is a result of not only more intensive treatment but also less tumor cell contamination of the graft collected after the first ASCT (15).

We cannot exclude a selection bias of this retrospective analysis. Patients with better performance status and less co-morbidities, as well as younger patients, were more often planned for T-ASCT. Our analysis was not designed to prove that T-ASCT is better than S-ASCT. Our goal was to confirm that tandem ASCT is feasible for majority of patients with newly diagnosed MM. The number of stem cells primed and isolated after first ASCT was sufficient and safe for performing the second ASCT, moreover with possible lower tumor cell contamination of graft.

The transplant-related mortality (TRM) was $6.3 \%$ for patients in the S-ASCT group and $4.6 \%$ for patients in the T-ASCT group. The TRM in our hands is comparable with other published data $(9,10,16)$.

In conclusion, our results with tandem autologous transplantation for patients with multiple myeloma proved that stem cell mobilization for the second transplant can be performed after the first one in majority of patients without increased toxicity. In the future better mobilization techniques using CXCR4 receptor antagonist plerixafor can enhance the number of collected PBSC and subsequently decrease number of mobilization failures. Our data suggest that second transplant with probably lower tumor cell contamination of the graft after $2^{\text {nd }}$ priming and in vivo purging can improve results of tandem ASCT in patients with MM. Alternative strategies with the use of novel drugs should be used for patients ineligible for tandem ASCT program.

Aknowledgements: We thank Dr. Tomáš Kollár for language revision of our article.

\section{References}

[1] ATTAL M, HAROUSSEAU JL, STOPPA AM, SOTTO JJ, FUZIBET JG et al. A prospective, randomized trial of autologous bone marrow transplantation and chemotherapy in multiple myeloma: Intergoupe Francais du Myelome. N Eng J Med 1996; 335: 91-97. http://dx.doi.org/10.1056/ NEJM199607113350204

[2] BLADE J, ROSINOL L, SUREDA A, RIBERA JM, DIAZ-MEDIAVILLA J et al. High-dose therapy intensification compared with continued standard chemotherapy in multiple myeloma patients responding to the initial chemotherapy: long-term results from a prospective randomized trial from the Spanish cooperative group PETHEMA. Blood 2005; 106: 3755-3759. http://dx.doi.org/10.1182/blood-2005-03-1301

[3] CHILD JA, MORGAN GJ, DAVIES FE, OWEN RG, BELL SE et al. High - dose chemotherapy with hematopoietic stem cell rescue for multiple myeloma. N Eng J Med 2003; 348: 1875-1883. http://dx.doi.org/10.1056/NEJMoa022340

[4] FERMAND JP, KATSAHIAN S, DIVINE M, LEBLOND V, DREYFUS F et al. High-dose therapy and autologous blood stem-cell transplantation compared with conventional treatment in myeloma patients aged 55 to 65 years: Long-term results of a randomised control trial from the Group MyelomeAutogreffe. J Clin Oncol 2005; 23: 9227-9233. http://dx.doi. org/10.1200/JCO.2005.03.0551

[5] PALUMBO A, BRINGHEN S, PETRUCCI MT, MUSTO P, ROSINI $\mathrm{F}$ et al. Intermediate-dose melphalan improves survival of myeloma patients aged 50 to 70 : results of randomized controlled trial. Blood 2004; 104: 3052-3057. http://dx.doi. org/10.1182/blood-2004-02-0408

[6] FERMAND JP, RAVAUD P, CHEVRET S, DIVINE M, LEBLOND V et al. High-Dose Therapy and Autologous Peripheral Blood Stem Cell Transplantation in Multiple Myeloma: Upfront or Rescue Treatment? Results of a Multicenter Sequential Randomized Clinical Trial. Blood 1998; 92: 3131-3136.

[7] LAHUERTA JJ, MATEOS MV, MARTINEZ-LOPEZ J, GRANDE C, RUBIA J et al. Busulfan $12 \mathrm{mg} / \mathrm{kg}$ plus melphalan $140 \mathrm{mg} / \mathrm{m} 2$ versus melphalan $200 \mathrm{mg} / \mathrm{m} 2$ as conditioning regimens for autologous transplantation in new diagnosed multiple myeloma patients included in the PETHEMA/ GEM2000 study. Haematologica 2010; 95: 1913-1920. http:// dx.doi.org/10.3324/haematol.2010.028027

[8] MOREAU P, AVET-LOISEAU H, HARROUSSEAU JL, ATTAL M. Current trends in autologous stem-cell transplantation for myeloma in the era of novel therapies. J Clin Oncol 2011; 29: 1898-1906. http://dx.doi.org/10.1200/ LCO.2010.32.5878

[9] CAVO M, TOSI P, ZAMAGNI E, CELLINI C, TACCHETTI $\mathrm{P}$ et al. Prospective, randomized study of single compared with double autologous stem-cell transplantation for multiple 
myeloma: Bologna 96 clinical study. J Clin Oncol 2007; 25: 2434-2441. http://dx.doi.org/10.1200/JCO.2006.10.2509

[10] ATTAL M, HAROUSSEAU JL, FACON T, GUILHOT F, DOYEN CH et al. Single versus double autologous stem-cell transplantation for multiple myeloma. N Eng J Med 2003; 349: 2495-2502. http://dx.doi.org/10.1056/NEJMoa032290

[11] GERTZ MA, LACY MQ, INWARDS DJ, GASTINEAU DA, TEFFERI A et al. Delayed stem cell transplantation for the management of relapsed or refractory multiple myeloma. Bone Marrow Transplant 2000; 26: 45-50. http://dx.doi. org/10.1038/sj.bmt.1702445

[12] HOSMER DW, LEMESHOW S. Applied survival analysis. Wiley: New York, 1999

[13] TRICOT G, JAGANNATH S, VESOLE D, NELSON J, TINDLE S et al. Peripheral blood stem cell transplants for multiple myeloma: identification of favorable variables for rapid engraftment in 225 patients. Blood 1995; 85: 588-596.
[14] Zhou P, Zhang Y, Martinez C, Kalakonda N, Nimer SD. Melphalan-mobilized blood stem cell components contain minimal clonotypic myeloma cell contamination. Blood 2003; 102: 477-479. http://dx.doi.org/10.1182/blood-2002$\underline{12-3674}$

[15] REGELINK JC, VAN ROESSEL CHM, VAN GALEN KPM, OSSENKOPPELE GJ, HUIJGENS PC et al. Long-term followup of tandem autologous stem-cell transplantation in multiple myeloma. J Clin Oncol 2010; 28: e741-e743. http://dx.doi. org/10.1200/JCO.2010.31.5515

[16] HUIJGENS PC, DEKKER-VAN ROESSEL HM, JONKHOFF AR, ADMIRAAL GC, ZWEEGMAN S et al. High-dose melphalan with G-CSF-stimulated whole blood rescue followed by stem cell harvesting and busulphan/cyclophosphamide with autologous stem cell transplantation in multiple myeloma. Bone Marrow Transplant 2001; 27: 925-931. http://dx.doi. org/10.1038/sj.bmt.1703013 